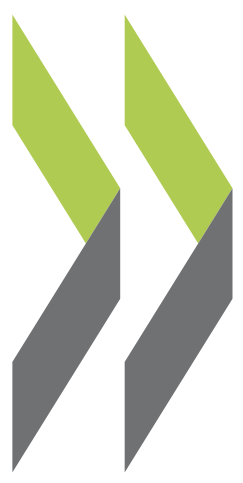

PEB Exchange, Programme on Educational Building 1999/15

\author{
An Update on Asset \\ Management Plans \\ in the United Kingdom
}

Mukund Patel

https://dx.doi.org/10.1787/444022103374 


\section{AN UPDATE ON ASSET MANAGEMENT PLANS IN THE UNITED KINGDOM}

This description of a major project currently underway in the U nited Kingdom to improve school buildings follows an article published in the February 1999 issue of PEB Exchange.

\section{Introduction}

Government, because of its commitment to education, is making significant additional capital funding available to the schools sector. O ver the next three years, through various policy initiatives, about GBP 6 billion will be arailable to clear the maintenance backlog and improve school buildings. It is important that this money is used efficiently and as effectively as possible.

Capital improvements have a key part to play in helping to raise educational standards. These, together with improved maintenance and better use of premises, are part of the agenda of reform and modernisation of the country's schools, helping to make them become focal points of learning for the whole community. As part of this process, Authorities and schools will need to develop plans for the efficient procurement, management and improvement of capital assets, using innovative, sustainable and energy-efficient solutions.

A key element in ensuring that this happens will be the Asset M anagement Plans (AMPs) prepared by Authorities in partnership with schools and dioceses. AMPs will provide the means through which likely future needs are assessed, criteria for prioritisation are set and informed decisions on local spending are made. Decisions based on AMPs should lead to greater efficiency in the use of capital and to improved educational outcomes. The decisions will be more transparent than at present and should therefore be seen to be fairer.

Where sound processes and good AM Ps are in place, it will be possible for the Department for Education and Employment ( $D$ fEE) to operate with a lighter touch, giving Authorities more assurance of predictable longer term funding and greater discretion to pursue national and locally agreed priorities.

\section{AMPs framework}

Local Education Authorities (LEAs) will be responsible for preparing the Asset Management Plans, which will cover all types of state-funded schools in their boundaries. An AM P will provide an agreed basis for local decisions on spending priorities. AMPs will have the following main elements:

1. Local policy statement - This will set out how an Authority proposes to develop its AMP and the roles and responsibilities of all partners, including schools and the dioceses.

2. Condition surveys - These will provide a systematic, informed and objective assessment of the physical state of the premises and the work needed to bring the premises up to a suitable state of repair.

3. Suitability assessment - This will focus on how well premises are helping in delivery of the curriculum and contributing towards raising educational standards at the school.

4. Sufficiency needs - This will identify any capital works arising from the Authority's statutory duty to provide sufficient school places and also the need to remove surplus places.

5. Determining priorities- Prioritising need is going to be the most important and sensitive task in developing AM Ps. Authorities will need to work with schools and dioceses to develop Authoritywide views on premises priorities. These views can be used as the basis for identifying and prioritising the most serious and urgent needs at specific establishments.

6. O ption appraisal - Having prioritised need, Authorities will need to work up feasibility studies and consider the costs and benefits of alternative solutions. For some repairs and minor capital works, the solutions to particular premises problems may be clear cut. For larger projects, however, consideration of a range of options is needed. Analysis of the main lifecycle costs and benefits of each option will help to establish the most effective and economic solution.

7. Implementation - This stage will involve procuring the buildings in efficient and economic ways. Authorities should aim to provide quality buildings based on sustained development concepts. 


\section{Appraisal of AMPs}

D fEE will appraise all LEAs' Asset M anagement Plans to ensure that they are robustly put together and that LEAs' partners were involved in the process. It will also check AM Ps for consistency and robustness, if necessary, by checking a sample of schools and asking for further information on some schools.

Appraisal will involve marking each AM P. W here the AM $P$ is up to the required standard the LEA will receive its capital allocation, which it can then use to address its priorities. It may also be assured of funding over a number of years.

Where the AMP is not up to standard, D fEE will require further information on individual projects and will then determine and direct the funding.

D fEE will issue guidance on how it will carry out the appraisal of AM Ps.

\section{Programme}

The following guidance has been issued so far:

Section 1 - AMPs framework

Section 2 - Premises information and data systems

Section 3 - Condition survey

Section 4 - Suitability assessment

Time-scales for remaining guidance are as follows:

Section 5 - Sufficiency guidance December 1999

Section 6 - Guidance on options appraisal March 2000

Section 7 - Guidance on implementation March 2000

DfEE hopes that $90 \%$ of Local Authorities will have fully developed AM Ps by end of year 2000.

This article was contributed by Mukund Patel, $\mathrm{H}$ ead of the Architects \& Building Branch of the Department for Education and Employment, United Kingdom.

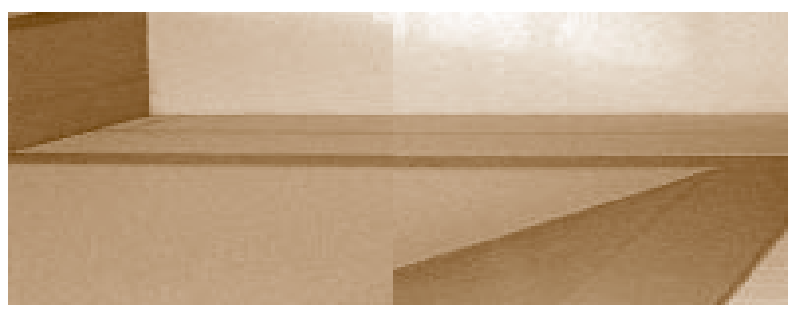

QUEBEC

ENERG Y PERFO RMANCE

CONTRACTS FOR THE

SCHO OL SYSTEM: NEW

RULES OFTHE GAME

\section{Introduction}

This article takes a brief look at the new rules covering energy performance contracts for Quebec school boards. It discusses the following questions:

- the school boards' educational buildings;

- the school boards' energy performance;

- regulations with regard to the awarding of contracts in the public and quasi-public sectors;

- the new rules for awarding energy performance contracts in education.

\section{The school boards' educational buildings}

From a legal standpoint, a school board is a legal entity under public law. It is administered by a committee made up of people who are elected or appointed under the law on school elections. In addition to ensuring that the pupils that come within their sphere receive the educational services to which they are entitled, school boards are also responsible for:

- purchasing or renting the movables and real estate required in order to carry on their activities and those of their teaching establishments;

- building, repairing and maintaining their movables and real estate;

- deciding how their goods should be used and administering them.

There were 152 school boards during the 1997/98 school year, but with the mergers and remapping of the areas covered by school boards, their numbers have fallen to 72 since 1 July 1998. Previously, there were a number of very small school boards, covering barely 1000 pupils, and some very big ones like the M ontreal Catholic School Board, with 75000 pupils. As a result of the mergers, the smaller ones have all but disappeared, and the average board is responsible for some 16000 pupils.

In the 1998/99 school year, the school boards owned 3996 buildings; they were put to use as follows:

\begin{tabular}{l|c|}
\hline U se & Number of buildings \\
Teaching & 3459 \\
Administrative centres & 138 \\
Sports chalets, day nurseries, warehouses & 116 \\
Residences & 30 \\
\hline & $\mathbf{3 7 4 3}$ \\
\hline
\end{tabular}

